\title{
Evaluation of Brain Activation (NeuroSPECT) by Uni- and Bilateral Auditory Stimulation in Patients with Conductive Hearing Loss and Bilateral Bone Conduction Devices
}

\author{
Marcos V Goycoolea ${ }^{1}$, Sonia Neubauer ${ }^{2}$, Raquel Levy ${ }^{3}$, Jacqueline Cornejo ${ }^{4}$, Byanka Cagnacci ${ }^{5}$, Catherine Catenacci ${ }^{6}$
}

\begin{abstract}
Background:This prospective study evaluated sound localization and brain responses to monaural and binaural stimulation via bone conduction devices in 3 individuals with bilateral conductive hearing loss ( 1 acquired and 2 congenital).

Aims and objectives: To determine the (1) Cortical areas that are activated with pure tones. (2) Potential benefits of bilateral devices.

Materials and methods: A new audiological test is described (real-life lateralization test) and applied. NeuroSPECT studies were done using pure tones delivered via bone conduction devices (Baha Attract) stimulating monaurally and binaurally. The tests were performed 2-4 months after the placement of the second device.

Results: The use of unilateral devices as well as bilateral devices under our testing conditions did not improve sound localization. There was improvement in lateralization with bilateral devices. In the three subjects, cortical activation with binaural auditory stimulation with the Baha Attract occurred in the same auditory areas compared with monaural stimulation. However, while in the individual with acquired loss, the degree of activation was less intense in binaural compared to monaural stimulation; in the congenital cases, binaural stimulation resulted in summation of stimuli.

Conclusion: In congenital bilateral conductive hearing losses that have not been stimulated early, there are central auditory areas that are deprived. Even if these are only two cases, this is suggestive of the importance of bilateral early auditory stimulation in cases of congenital conductive hearing losses and supportive of the use of bilateral rather than unilateral devices.

Keywords: Adequate sound stimulation, Bilateral bone conduction devices, Bilateral conductive hearing loss, Binaural hearing, Early auditory stimulation, Language development, Real-life lateralization test, Sensory deprivation, Sound lateralization tests, Symmetric hearing, Timely stimulation.
\end{abstract}

International Journal of Head and Neck Surgery (2021): 10.5005/jp-journals-10001-1410

\section{INTRODUCTION}

Having an auditory pattern of behavior based on two ears is essential for sound localization, quality of hearing, understanding in groups, and with ambient noise. ${ }^{1-5}$ It is clearly established that in patients with bilateral and/or asymmetric sensorineural hearing loss, sound localization and better quality of hearing can be obtained with bilateral hearing aids and/or cochlear implants. ${ }^{2-9}$ Moreover, in children with bilateral congenital sensorineural hearing losses, there is ample evidence available to indicate that early auditory stimulation improves auditory input to the brain and facilitates language development., ${ }^{9,10}$

When it comes to bilateral conductive hearing losses treated with bone conduction devices, two questions come to mind: (1) Is there a better ability to hear and to localize sound with bilateral compared to unilateral bone conduction auditory devices? (2) Is there any basis for early use of these devices in order to provide bilateral auditory stimulation in congenital conductive hearing losses?

To answer these and other related questions, we have developed a systematic and sequential approach by means of evaluating brain activation (neuroSPECT) by auditory stimuli. We previously established a normal database with monaural stimulation (stimulating only one ear) in 10 individuals with normal hearing. ${ }^{11}$ We observed that the response was bilateral; therefore, there are ipsilateral and contralateral pathways to the cortex.

\footnotetext{
${ }^{1,3}$ Department of Otolaryngology, Clínica las Condes and Clínica Universidad de Los Andes, Santiago, Chile

${ }^{2,4}$ Nuclear Medicine, Clínica Las Condes, Santiago, Chile

${ }^{5}$ Latin American Division, Cochlear Latin America, Panama

${ }^{6}$ Department of Otolaryngology, Clínica Universidad de los Andes, Santiago, Chile
}

Corresponding Author: Marcos V Goycoolea, Department of Otolaryngology, Clínica las Condes and Clínica Universidad de Los Andes, Santiago, Chile, Phone: +569 63536353, e-mail: marcos. goycoolea@gmail.com

Howtocite this article:Goycoolea MV, NeubauerS, Levy R, etal. Evaluation of Brain Activation (NeuroSPECT) by Uni- and Bilateral Auditory Stimulation in Patients with Conductive Hearing Loss and Bilateral Bone Conduction Devices. Int J Head Neck Surg 2021;12(1):22-30.

Source of support: Nil

Conflict of interest: Cochlear Corporation provided the devices free of charge for the patients. All members of the clinical team did the surgical, audiological and imagenological procedures free of charge and did not receive any compensation (direct or indirect) from Cochlear Corporation.

The central responses were both of activation and inhibition, andin addition to the auditory areas-other areas of the cortex were activated. We then did the study in these individuals, ${ }^{12}$ stimulating both ears at the same time (binaural stimulation). The areas that 
were activated were the same than with monaural stimulation; however, with binaural stimulation, there was less inhibition, and the activation was less intense. These observations were suggestive that binaural stimulation did not translate in summation but in a better integration of stimuli, and that binaural hearing required less perfusion and seemingly less effort of the central nervous system.

In the present study, we evaluate sound localization and brain activation (neuroSPECT) by pure tones in three individuals with bilateral conductive hearing losses (one with acquired and two with congenital losses) who have bilateral bone conduction hearing devices (Baha Attract). These evaluations are done with monaural and binaural stimulation.

\section{Materials and Methods}

This study was submitted to and approved by the Ethics Committee of Clínica Las Condes.

\section{Subjects}

Three right-handed volunteers with bilateral conductive hearing loss, who have bilateral bone conduction hearing devices (Baha Attract), were included in this study. One female (case 1) with acquired hearing loss secondary to long-standing recurrent otitis media and two males (patients 2 and 3) with congenital bilateral conductive hearing loss secondary to congenital atresia of the ears who had not used amplification. Case 1: Female born on October 24, 1978. Left Baha March 2013; right Baha October 2018. Case 2 was a male born the on May 23, 1988. He had his left device placed in March 2013 and his right in early November 2018. Case 3 was a male born on December 7, 2005. He had his left device in May 2012 and his right in mid-October 2018.

\section{Tests}

- Audiometry. Their hearing was tested (pure tone audiogram and speech discrimination) in a soundproof room with and without their bilateral bone conduction devices (BCDs).

- NeuroSPECT Testing. Volunteers were tested twice. (1) Left ear with the bone conduction device on and the right bone conduction device off. (2) With both bone conduction devices on.

Ten minutes prior to testing, the volunteers were premedicated with $500 \mathrm{mg}$ oral potassium perchlorate and their right antecubital vein was cannulated. In a sound-proof, dimmed light room a pure tone was delivered at $50 \mathrm{~dB}$ above threshold during 2 minutes in sound field by means of a G16 Grason-Stadler audiometer. Simultaneously, $25 \mathrm{mCi}(925 \mathrm{mBq})$ of Tc99m - hexamethyl-propylenamine-oxime (HMPAO) (Ceretec ${ }^{\mathrm{TM}}$ ) were injected intravenously with bolus technique. HMPAO is initially lipophilic crossing easily the blood-brain barrier with a high degree of extraction to the intracellular space. After 2 minutes, it changes to the hydrophilic optic meso and becomes trapped in the brain tissue. SPECT images correspond to the cerebral perfusion at the moment of its administration even if the imaging is done later. During the 2 minutes uptake time of HMPAO, the subjects were instructed to concentrate on listening to the sound and to sit as motionless as possible. The volunteers confirmed that they had heard the tone during the whole duration of the test. Sixty minutes after the injection, the neuroSPECT images were gathered on a double-head Siemens ECAM, with LEHR collimators and processed applying a volume normalization with the Talairach technique (Neurogam, Segami Corp., Columbia, MD, USA) based on the method developed by Mena et al. and has been reported previously. ${ }^{11-13}$ Images of a voxel-by-voxel comparative analysis with a normal age-matched control group were obtained, and cortical perfusion values were expressed as standard deviation (SD) above or below the normal mean for the corresponding age group. We also used 15 automatically defined regions of interest (ROIs), corresponding to cortical projected Brodmann areas, as reference for quantitative functional cerebral perfusion evaluation (maximum, minimum and mean). The projection of this template is automatic, and therefore the reproducibility of the results is $100 \%$.

\section{Case 1}

Left ear monaural stimulation September 4, 2018. Binaural test December 18, 2018. 2 months post-right Baha.

\section{Case 2}

Left ear monaural stimulation September 6, 2018. Binaural test December 11, 2018. 4 months post-second Baha.

\section{Case 3}

Left ear monaural stimulation September 6, 2018. Binaural test December 11, 2018. 2 months post-second Baha.

- Sound lateralization test. We designed a test which we termed: "Real-life lateralization test" (RLLT). The test was initially validated in 10 normal hearing volunteers, and then, the three subjects with bilateral conductive hearing losses were tested. The test is as follows: Our institution has six elevators located side by side in the lobby of the building. They are constantly in use because there is heavy transit of persons. The elevator arrival is accompanied by a $70 \mathrm{~dB}$ ring and the elevators arrive in an aleatory manner. The ambient noise is $63 \mathrm{~dB}(40-75 \mathrm{~dB})$. The subject is placed in front of the elevators (in the middle) with eyes covered and is tested either with one ear blocked or both ears open. Twenty tests are done per subject. In the patients with conductive hearing loss, the tests are done with one bone conduction hearing device on or with both devices on.

\section{Results}

\section{Audiometry}

Patient I. Acquired bilateral conductive hearing loss. Figure 1: Without BCDs. Figure 2: With BCDs.

Patient II. Congenital bilateral conductive hearing loss. Figure 3: Without BCDs. Figure 4: With BCDs.

Patient III. Congenital bilateral conductive hearing loss. Figure 5: Without BCDs. Figure 6: With BCDs.

\section{NeuroSPECT Testing}

- Patient I. Acquired bilateral conductive hearing losses. With monaural and binaural stimulation. Figure 7.

- Patient II. Congenital bilateral conductive hearing loss. With monaural and binaural stimulation. Figure 8.

- Patient III. Congenital bilateral conductive hearing loss. With monaural and binaural stimulation. Figure 9.

In the patient with acquired bilateral conductive hearing loss cortical activation with binaural auditory stimulation with the Baha Attract occurred in the same auditory areas than with monaural 


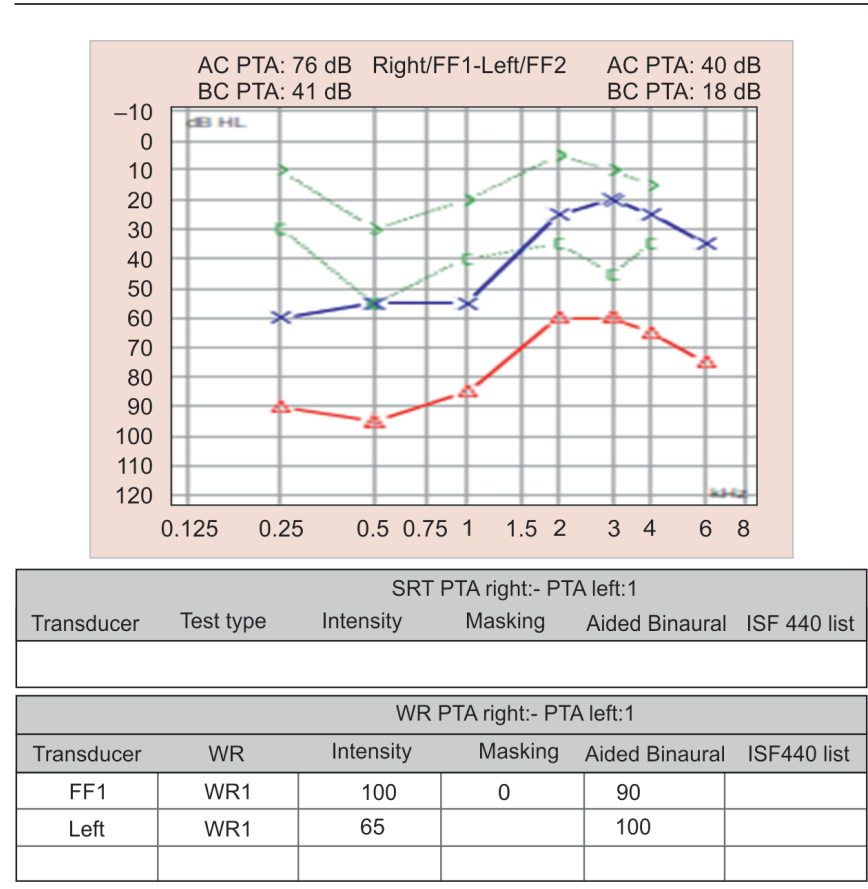

Fig. 1: Patient I: Acquired bilateral conductive hearing loss without bone conduction devices (BCDs)

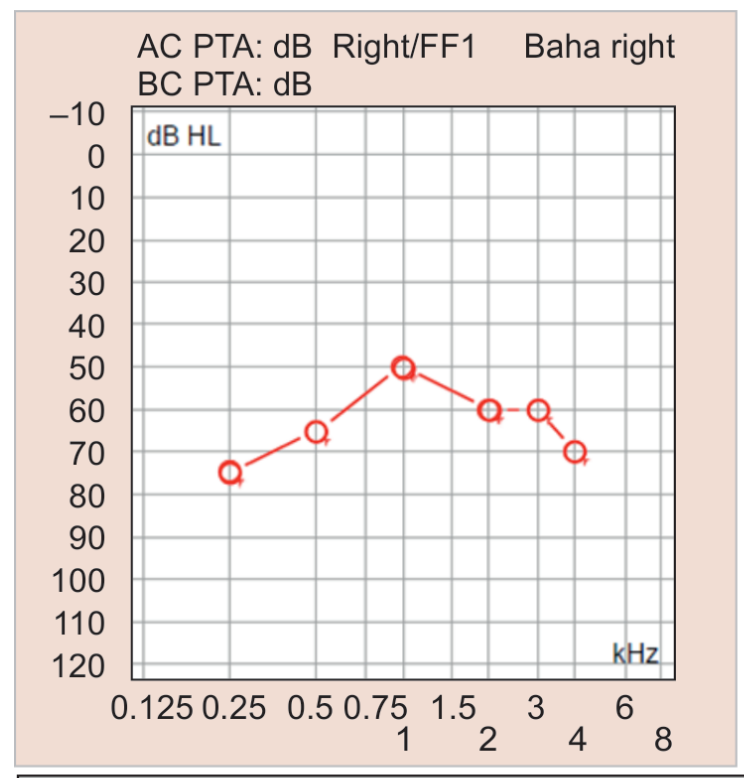

stimulation but the degree of activation was less intense in binaural compared to monaural stimulation. In other words, binaural stimulation did not result in summation of stimuli but in integration. In brief, Binaural use of Baha Attract in acquired conductive hearing loss requires less perfusion and seemingly less effort by the central nervous system (Fig. 7)

In the patients with congenital conductive hearing losses, activation with monaural and binaural stimulation occurred in the same areas. However, binaural stimulation resulted in summation of stimuli, suggesting that in these two individuals with congenital conductive hearing losses, which have not been stimulated early, there are central auditory areas that are deprived (Figs 8 and 9).

\section{Sound Lateralization Test}

Normal hearing patients (20 tests; 10 monaural, 10 binaural).

\begin{tabular}{lll}
\hline Age & \% error binaural & \% error monaural \\
\hline 56 & 30 & 60 \\
30 & 20 & 60 \\
28 & 10 & 60 \\
21 & 20 & 70 \\
21 & 30 & 70 \\
23 & 40 & 80 \\
22 & 40 & 70 \\
\hline
\end{tabular}

Normal hearing individuals tested ranged from 22 to 56 years

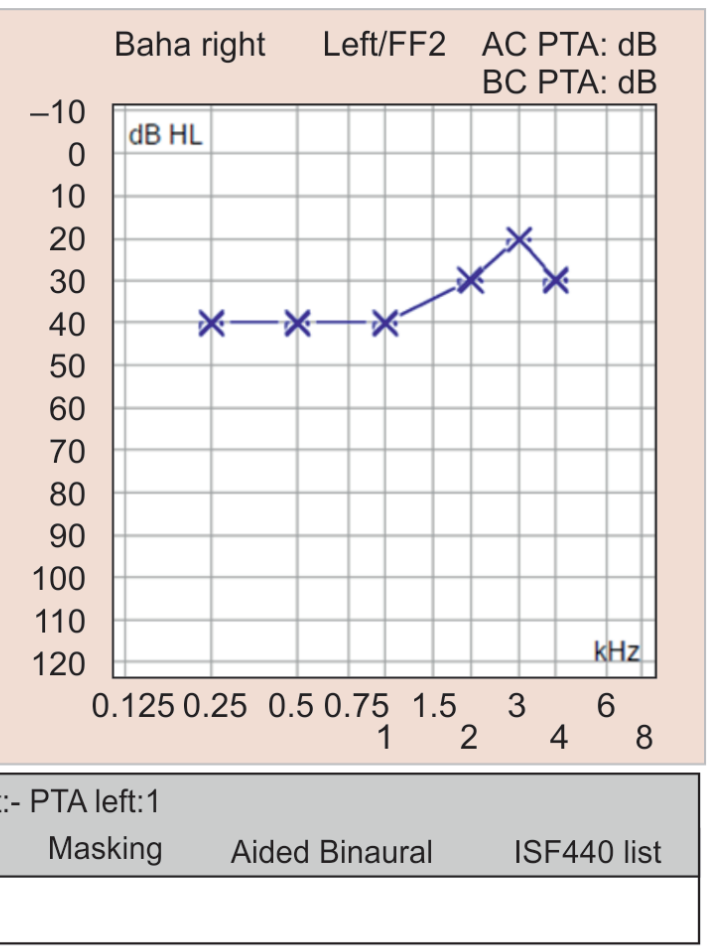

\begin{tabular}{|c|c|c|c|c|c|c|}
\hline \multicolumn{7}{|c|}{ WR PTA right:- PTA left:1 } \\
\hline Transducer & WR & \multicolumn{1}{c|}{ Intensity } & Masking & Score Aided Binaural ISF440 list \\
\hline FF1 & WR1 & 55 & 55 & 56 & & \\
\hline Left & WR1 & 55 & & 100 & & \\
\hline & & & & & & \\
& & & & & & \\
\hline
\end{tabular}

Fig. 2: Patient I: Acquired bilateral conductive hearing loss with $B C D s$ 


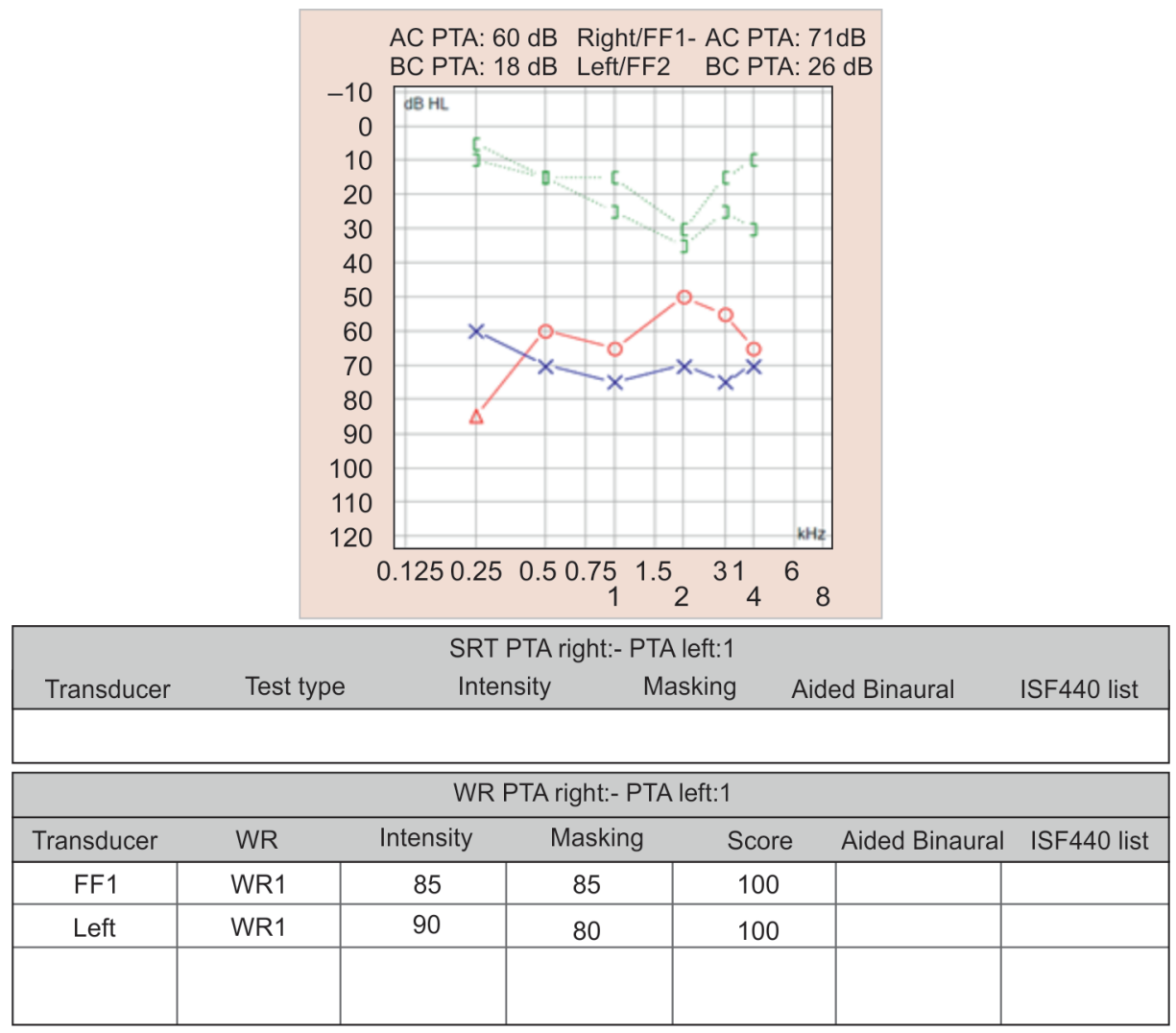

Fig. 3: Patient II: Congenital bilateral conductive hearing loss without BCDs

Patients with bilateral conductive hearing loss and bilateral BAHA. (20 tests; 10 monaural, 10 binaural).

\begin{tabular}{lll}
\hline Year of birth & \% error binaural & \% error monaural \\
\hline $\begin{array}{l}1978 \text { acquired loss } \\
\text { (case } 1 \text { ) }\end{array}$ & 70 & 80 \\
$\begin{array}{l}1988 \text { congenital loss } \\
\text { (case } 2 \text { ) }\end{array}$ & 40 & 70 \\
$\begin{array}{l}2005 \text { congenital loss } \\
\text { (case } 3 \text { ) }\end{array}$ & 70 & 80 \\
\hline
\end{tabular}

\section{Discussion}

The sense organs connect us with the environment, allowing external stimuli (information) to get into the nervous pathways and reach the cerebral cortex, where the information is stored and processed, and a functional relationship between the individual and the outside world is established. ${ }^{2}$ The sense of hearing connects us with the outside world in terms of sound, and an important part of this connection is sound localization. ${ }^{2,14}$ Moreover, to be able to locate the sound source, it is essential to listen with two ears since with one ear (e.g., single sided deafness) is not possible. However, these sound localization observations generally refer to the case of single-sided deafness and not to asymmetric or bilateral conductive losses.

It is of interest that the normal hearing individuals tested had difficulties with sound localization under our testing conditions. This is suggestive and supportive that in some of our crowded environments full of ambient noise, normal hearing individuals have difficulties in localizing sound and in understanding. Thus, this type of testing reflects our real hearing situation in environments that are quite common and supports the idea of the need of achieving optimal bilateral symmetric hearing. In the case of our three subjects with bilateral conductive hearing loss with bilateral bone conduction devices, the use of bilateral devices - under our testing conditions-improved sound localization but not significantly; however, the subjects felt that there was improvement, but the testing conditions were difficult. Perhaps since they were tested only between 2 and 4 months after surgery, the nervous system had not fully adapted to this new reality. Although a unilateral bone conduction device in this case provided some degree of bilateral (asymmetric) auditory stimulation, this did not suffice for sound localization. Ambient noise is a significant challenge for hearing and requires an optimal sense of hearing. When it comes to owls that hunt mice based on auditory clues, the question of how efficient an owl would be in hunting mice with ambient noise can also be raised.

Our NeuroSPECT study of the subject with acquired bilateral conductive hearing loss, cortical activation with binaural auditory stimulation with the Baha Attract occurred in the same auditory areas than with monaural stimulation and the degree of activation was less intense in binaural compared to monaural stimulation, the same as in normal hearing individuals. ${ }^{12}$ In other words, binaural stimulation did not result in summation of stimuli but in integration. However, in the patients with congenital conductive hearing losses, although activation with monaural and binaural stimulation occurred in the same areas, binaural stimulation resulted in summation of stimuli. This is suggestive that in patients with congenital conductive hearing losses deprived of early stimulation, there are dysfunctional central auditory areas. Even if the findings 


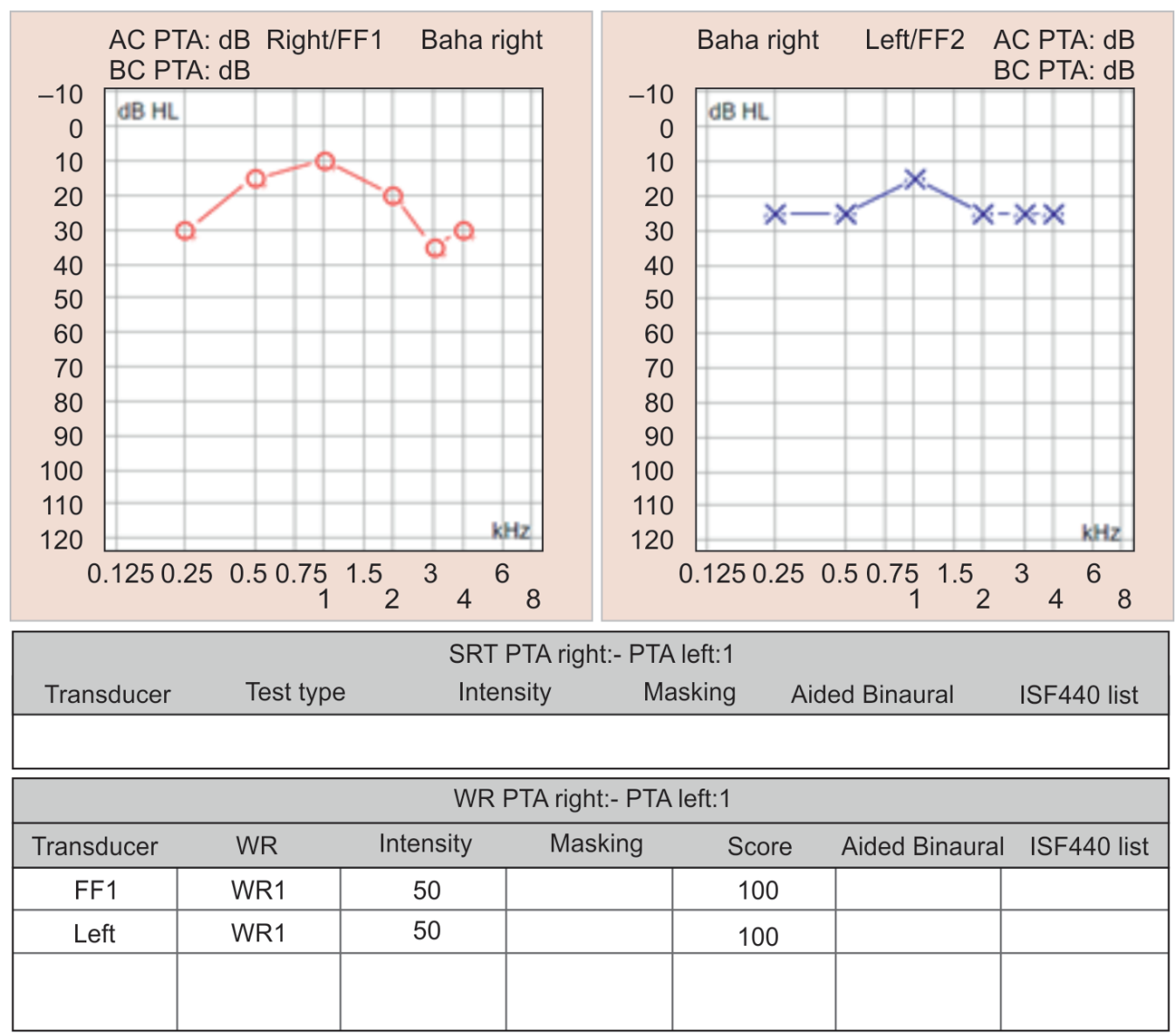

Fig. 4: Patient II: Congenital bilateral conductive hearing loss with BCDs

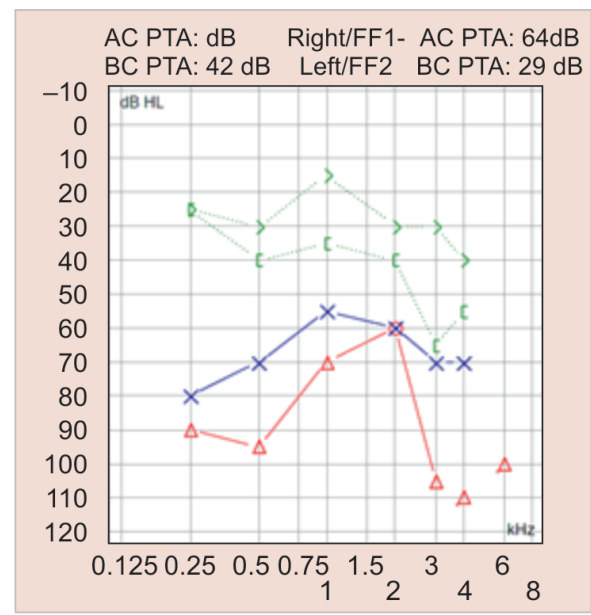

\begin{tabular}{|c|c|c|c|c|c|c|}
\hline Transducer & Test type & $\begin{array}{c}\text { SRT PTA right:- PTA left:1 } \\
\text { Intensity }\end{array} \quad$ Masking & Aided Binaural & ISF440 list \\
\hline \multicolumn{7}{|c|}{ WR PTA right:- PTA left:1 } \\
\hline \hline \multicolumn{70}{|c|}{ Intensity } & Masking & Score & Aided Binaural ISF440 list \\
\hline Transducer & WR & 100 & 75 & 56 & & \\
\hline FF1 & WR1 & 100 & & 96 & & \\
\hline Left & WR1 & 90 & & & & \\
\hline & & & & & & \\
\hline
\end{tabular}

Fig. 5: Patient III: Congenital bilateral conductive hearing loss without $B C D$ s 


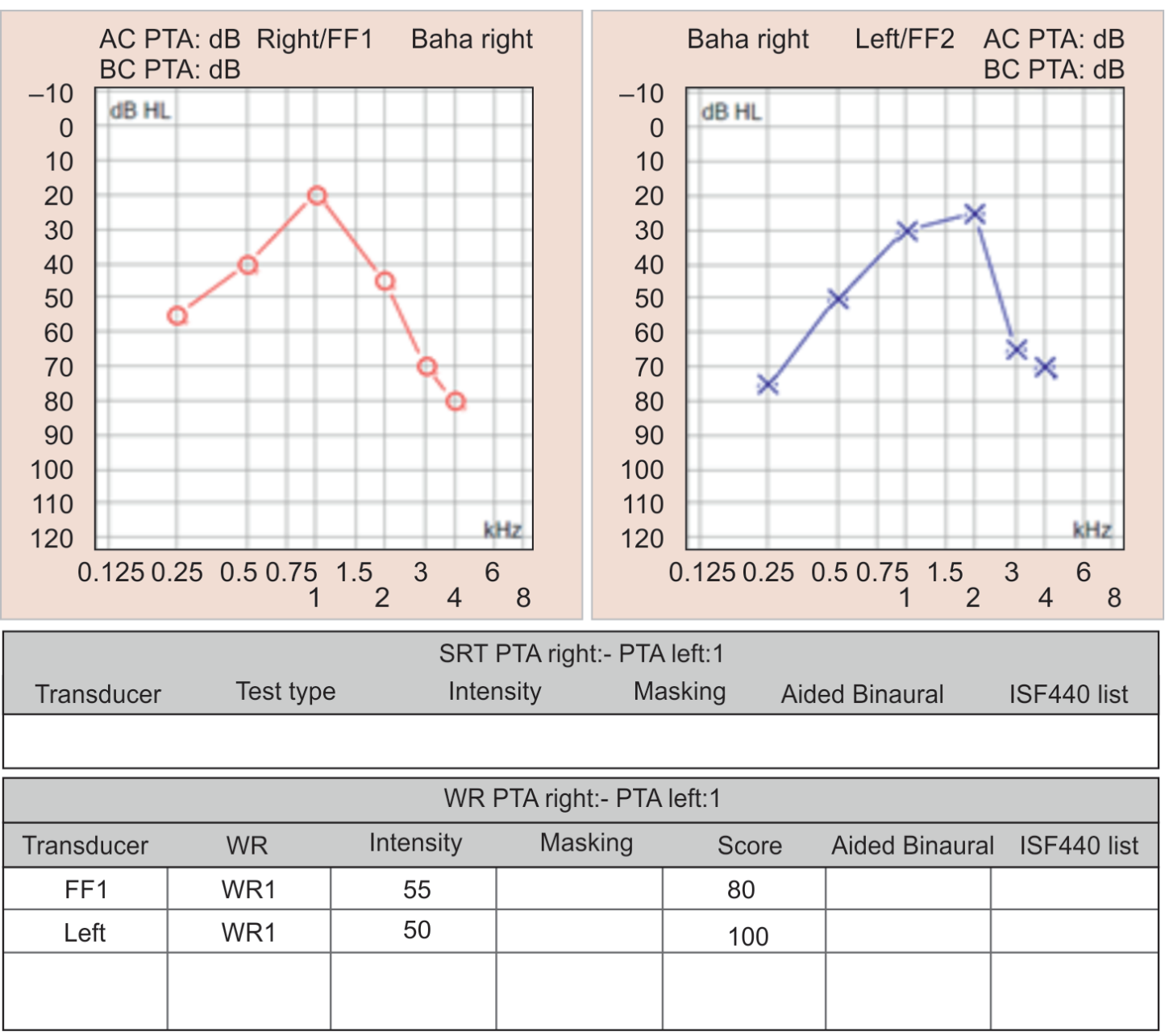

Fig. 6: Patient III: Congenital conductive hearing loss with BCDs

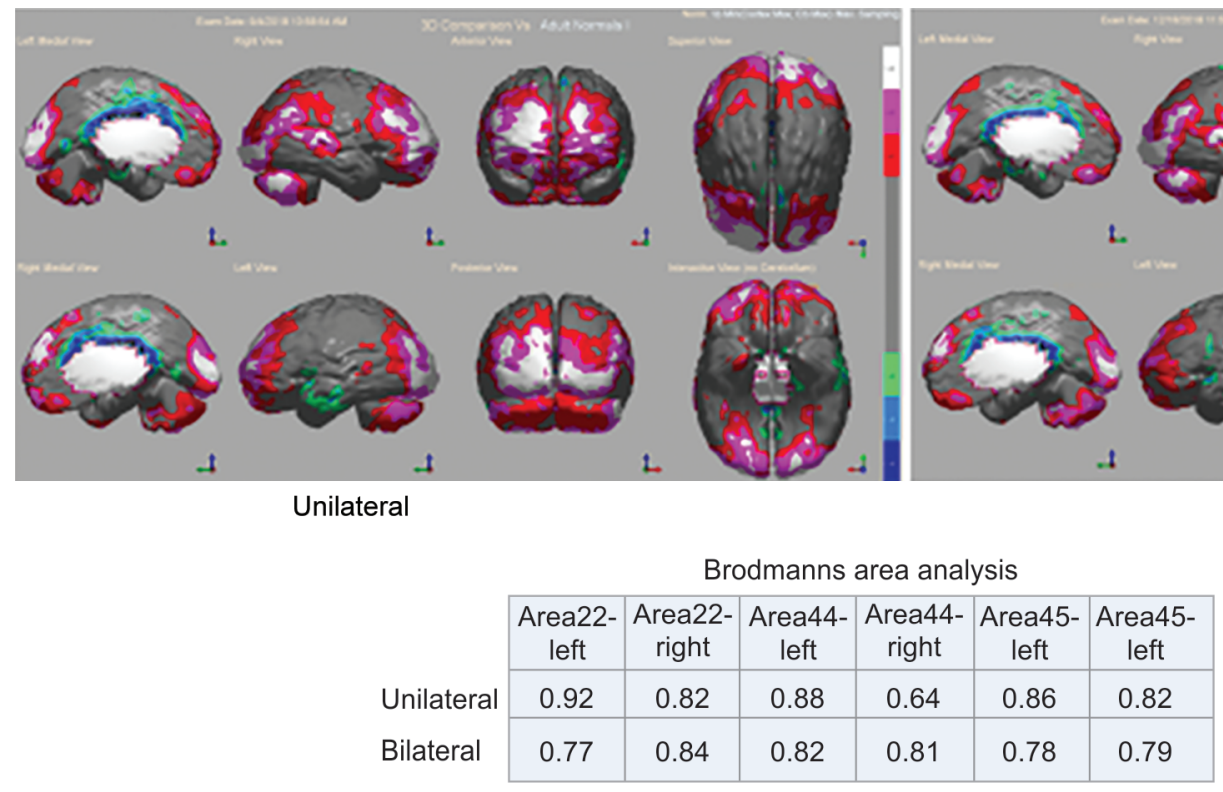

Fig. 7: Patient l: Acquired bilateral conductive hearing loss with monaural and binaural stimulation 


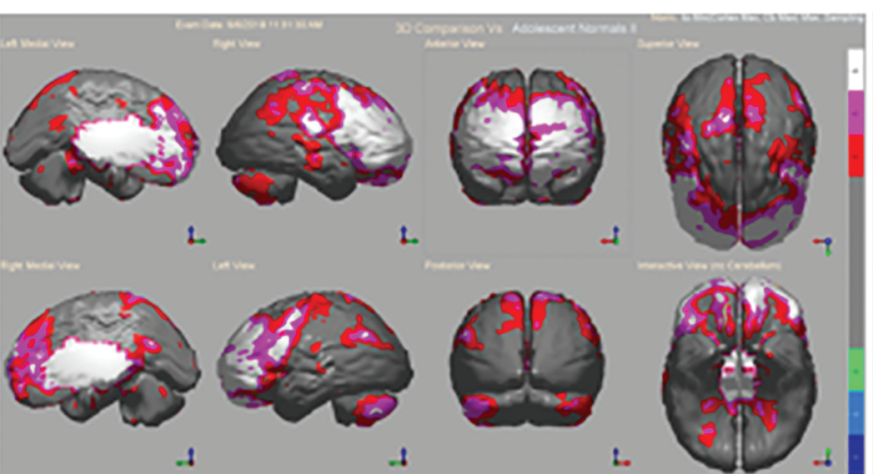

Unilateral left stimulation

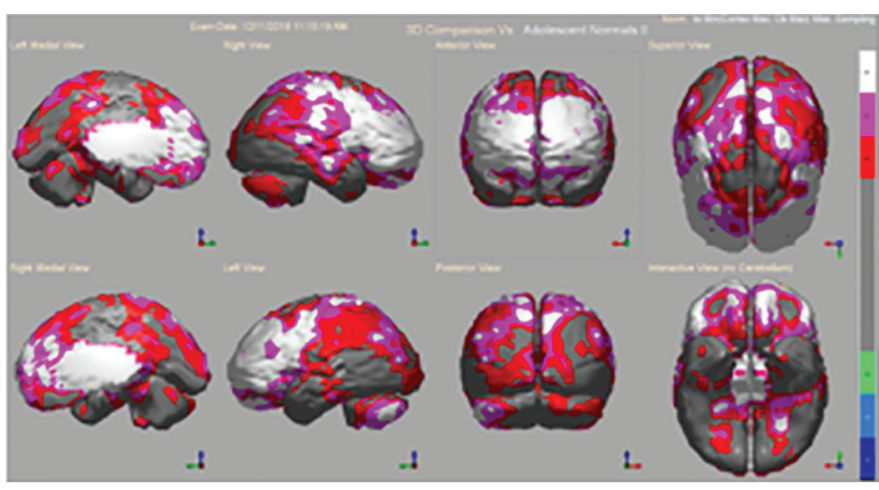

Bilateral

\begin{tabular}{l|c|c|c|c|c|c|}
\multicolumn{7}{c|}{ Brodmanns area analysis } \\
\cline { 2 - 7 } & $\begin{array}{c}\text { Area22- } \\
\text { left }\end{array}$ & $\begin{array}{c}\text { Area22- } \\
\text { right }\end{array}$ & $\begin{array}{c}\text { Area44- } \\
\text { left }\end{array}$ & $\begin{array}{c}\text { Area44- } \\
\text { right }\end{array}$ & $\begin{array}{c}\text { Area45- } \\
\text { left }\end{array}$ & $\begin{array}{c}\text { Area45- } \\
\text { left }\end{array}$ \\
\cline { 2 - 7 } Unilateral & 0.87 & 0.82 & 0.80 & 0.77 & 0.75 & 0.78 \\
\cline { 2 - 7 } Bilateral & 0.87 & 0.92 & 0.91 & 0.96 & 0.92 & 0.96 \\
\hline
\end{tabular}

Fig. 8: Patient II: Congenital bilateral conductive hearing loss with monaural and binaural stimulation
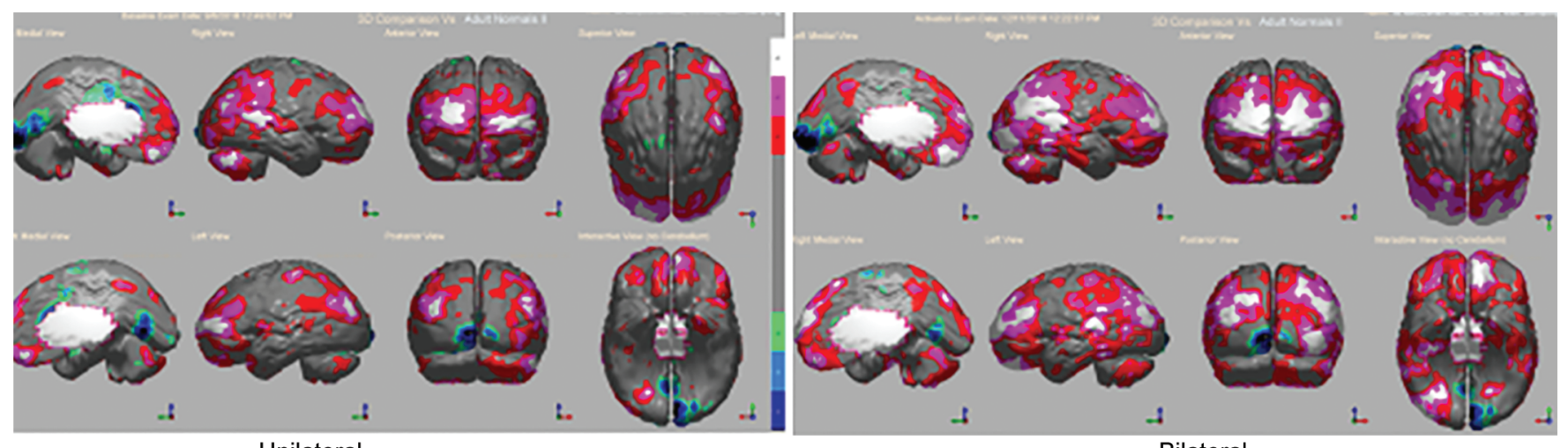

Unilateral

Brodmanns area analysis

\begin{tabular}{l|c|c|c|c|c|c|} 
& $\begin{array}{c}\text { Area22- } \\
\text { left }\end{array}$ & $\begin{array}{c}\text { Area22- } \\
\text { right }\end{array}$ & $\begin{array}{c}\text { Area44- } \\
\text { left }\end{array}$ & $\begin{array}{c}\text { Area44- } \\
\text { right }\end{array}$ & $\begin{array}{c}\text { Area45- } \\
\text { left }\end{array}$ & $\begin{array}{c}\text { Area45- } \\
\text { left }\end{array}$ \\
\cline { 2 - 7 } Unilateral & 0.88 & 0.89 & 0.86 & 0.85 & 0.85 & 0.81 \\
\cline { 2 - 7 } Bilateral & 0.92 & 0.89 & 0.86 & 0.88 & 0.85 & 0.86 \\
\hline
\end{tabular}

Fig. 9: Patient III: Congenital bilateral conductive hearing loss with monaural and binaural stimulation

are only of two cases, they are suggestive and supportive of the importance of bilateral early auditory stimulation in congenital conductive hearing losses.

Lack of sensory input to the cortex results in a sensory deprivation (deficit). In children with sensorineural hearing loss, stimuli (sensory input) fail to fully reach the auditory pathways and cortex because of a failure in the receptor. ${ }^{15-18}$ In the socially and educationally deprived children, the receptors and the transmission system are fine, but there is lack of input to the cortex because of poor stimulation. ${ }^{19}$ In our subjects with congenital bilateral conductive hearing loss, there was also lack of input to the cortex but because of lack of "transmission" (even if the sensory receptors were normal). Thus, although the causative mechanism is different in these three scenarios, the end result is the same: a sensorydeprived cerebral cortex secondary to lack of early stimulation.
In the case of deprivation by sensorineural hearing loss, early cochlear implantation and early stimulation has been shown to be essential. Children implanted before the age of 2 perform significantly better in all tests, compared to children implanted at an older age, and acquire auditory skills that are closer to their peers with normal hearing. ${ }^{6,15,20,21}$ Early sensory stimulation improves auditory input to the brain and facilitates language development. ${ }^{6}$ Children implanted before the age of two have faster rates of spoken language acquisition than children implanted after that age, and there is a sensitive or critical period for speech development in which early stimuli are essential. $6,9,16-18,20,21$ This is also true for children with hearing loss who do not need to be implanted but are intervened with rehabilitation at early stages. Moeller ${ }^{22}$ evaluated vocabulary and verbal reasoning skills in children with hearing losses who were subjected to a comprehensive intervention 
program and observed better vocabulary and reasoning skills in children that were enrolled at earlier stages.

Regarding late intervention, around the age of 5, open-set word recognition performance has been shown to be significantly better for children implanted before the age of 5 compared to children implanted after age $5 .^{23,24}$ Moreover, Frush and Svirsky ${ }^{21}$ have reported that from a practical perspective, language development will occur in children implanted later in life, but on the average their rate of acquisition will be poorer, and they will continue to lag behind their normal peers for a longer time. This is the case in normal hearing children who are educationally deprived. ${ }^{19}$

As mentioned, these three situations of cortical deprivation refer to children. On the other end, lack of auditory sensory stimulation also occurs in the elderly with hearing loss. The effects of hearing loss in the elderly also translate in a sensory deprived cortex that can be devastating and can potentially translate in communication and integration problems that can lead to isolation and eventually to loneliness, cognitive decline and even dementia. ${ }^{25-27}$ Since life expectancy has improved and the percentage of elderly persons has increased, ${ }^{25-27}$ cortical deprivation by hearing loss is gradually becoming a crucial issue for these aging individuals.

Additionally, we suggest that the intervention should consider stimulation beyond pure sound, since the auditory sensory process itself is not localized or isolated, but it is cortically global. This concept is supported by functional brain studies (neuroSPECT) with auditory stimuli with pure tones that show patterns of extensive cortical activation. ${ }^{11}$ Moreover, these studies have shown that central responses to auditory stimuli are bilateral and that the central auditory pathway is ipsilateral and contralateral and not necessarily symmetric. In addition, these central responses to auditory stimuli involve among others, executive frontal areas, visual and affective areas, areas of auditory association and auditory memory. ${ }^{11}$

Therefore, sound stimulation by itself is not enough. Placement of a cochlear implant is only a part of a global approach that necessarily involves a comprehensive rehabilitation and educational process. The same holds true for educationally deprived children, individuals using hearing aids, bone conduction devices, etc.

Although language depends on hearing, auditory stimuli by themselves are not sufficient stimulation for language development. Experience and social interaction are essential. Fromkin et al. ${ }^{28}$ described the cases of children who had lived in deprived environments of language for a prolonged period who despite normal hearing, failed to learn language. Moreover, despite language rehabilitation, they were not able to acquire full language abilities since their rehabilitation occurred past the critical periods of language learning. ${ }^{16,17}$

Since speech learning is dependent on social interactions, listening, speaking, and participating emotionally are essential. ${ }^{9}$ In the case of implanted children, environment and family language interactions have shown to be essential for language development. ${ }^{20}$ On the other end of the age spectrum, elderly individuals with hearing loss also require social interaction and rehabilitation in addition to hearing aids in order to maintain their neuronal circuits.

\section{Conclusion}

Regardless of the mechanism of occurrence (failure of receptors, of transmission, or because of poor stimuli), lack of sensory input to the cortex results in a sensory deprivation (deficit) that requires not only *adequate sound stimuli (*meaning also bilaterality and symmetry) applied timely (early) but also applied as part of an overall rehabilitation oriented to a global rehabilitation of neuronal circuits stimulating the whole cortex.

\section{References}

1. Goycoolea M, Mena I, Neubauer S. General Overview and Central transmission. Atlas of Otologic Surgery and Magic Otology Goycoolea M, ed., New Dehli, India: Jay Pee Brothers Medical Publishers; 2012. pp. 3-11.

2. Goycoolea M. The inner ear and understanding the message (central processing). The Music of the Spheres and the Magic of Hearing Goycoolea M, ed., Ciudad de Panamá, Panamá: Jay Pee Highlights Medical Publishers; 2017. pp. 55-118.

3. O'Shea M. Sensing, perceiving and acting. The Brain O'Shea M, ed., Oxford, England: Oxford University Press; 2005. pp. 64-83.

4. Goldsmith M. Hearing sound. Sound Goldsmith M, ed., Oxford England: Oxford University Press; 2015. pp. 52-68.

5. Ramos Macías Á, Borkoski-Barreiro SA, Falcón González JC, et al. Single-sided deafness and cochlear implantation in congenital and acquired hearing loss in children. Clin Otolaryngol 2018;44(2):138143. DOI: 10.1111/coa.13245.

6. Moreno-Torres I, Cid M, Santana R, et al. Estimulación temprana y desarrollo lingüístico en niños sordos con implante coclear: el primer año de experiencia auditiva. Logopedia 2011;1:56-75.

7. Papsin B, Gordon K. Bilateral cochlear implants should be the standard for children with bilateral sensorineural deafness. Curr Opinión Otolaryngol Head and Neck Surg 2008;16(1):69-74. DOI: 10.1097/ MOO.0b013e3282f5e97c.

8. Gordon K, Papsin B. Benefits of short interimplant delays in children receiving bilateral cochlear implants. Otol Neurotol 2009;30(3):319331. DOI: 10.1097/MAO.0b013e31819a8f4c.

9. Svirsky M, Teoh S, Neuburger H. Development of language and speech perception in congenitally profound deaf children as a function of age at cochlear implantation. Audiol Neurootol. 2004;9(4):224-233. DOI: 10.1159/000078392.

10. Sharma A, Glick H, Campbell J, et al. Cortical plasticity and reorganization in pediatric singlelsided deafness pre and postcochlear implantation: a case study. Otol Neurotol 2016;37(2):26-34. DOI: 10.1097/MAO.0000000000000904.

11. Goycoolea M, Mena I, Neubauer S. Functional studies of the human auditory pathway after monaural stimulation with pure tones. Establishing Nor Data Acta Oto-Laryng 2005;125(5):513-519. DOI: 10.1080/00016480510026250.

12. Goycoolea M, Mena I, Neubauer S. Functional studies (NeuroSPECT) of the human auditory pathway after stimulating binaurally with pure tones. Acta Otolaryngol 2011;131(4):371-376. DOI: 10.3109/00016489.2010.545076.

13. Mena I, Correa R, Nader A, et al. Bipolar affective disorders; assestment of functional brain changes by means of Tc99 HMPAO NeuroSPECT. Alasbimn J 2004. 6. Available from: http://www2.alasbimnjournal.cl/ alasbimn/CDA/sec_b/0,1206,SCID\%253D6213,00.html.

14. Goycoolea M, Levy R, Alarcón P, et al. "Oh Granny, what big two ears you've got!" "All the better to hear you with, my dear!" (Neuronal Circuit recovery with a cochlear implant). This issue.

15. Gordon KA, Jiwani S, Papsin B. Benefits and detriments of unilateral cochlear implant use on bilateral auditory development in children who are deaf. Front Psychol 2013. 1-24. DOI: 10.3389/ fpsyg.2013.00719.

16. Niparko JK, Tobey EA, Thal DJ, et al. Spoken language development in children following cochlear implantation. JAMA 2010;303(15):14981506. DOI: 10.1001/jama.2010.451.

17. Sharma A, Dorman MF, Spahr AJ. A sensitive period for the development of the central auditory system in children with cochlear implants: Implications for age of implantation. Ear Hear 2002;23(6):532-539. DOI: 10.1097/00003446-200212000-00004. 
18. Kral A, Sharma A. Developmental neuroplasticity after cochlear implantation. Trends Neurosc 2012;35(2):111-122. DOI: 10.1016/j. tins.2011.09.004.

19. Goycoolea M, Levy R, Bustamante M, et al. Chances of reversibility in early sensory deprivation of the homo vulnerabilis: a 5 year (and ongoing) prospective study. Acta Otolaryngol 2019;139(4):357-360. DOI: 10.1080/00016489.2018.1538566.

20. Ramos-Macías A, Borkoski-Barreiro S, Falcón-González JC. Results in cochlear implanted children before 5 years of age. A long term follow-up. Int J Pediat Otorhinolaryngol 2014;78(12):2183-2189. DOI: 10.1016/j.ijporl.2014.10.006.

21. Frush Holt R, Svirsky MA. An exploratory look at pediatric cochlear implantation: is earliest always best? Ear Hear 2008;29(4):492-511. DOI: 10.1097/AUD.0b013e31816c409f.

22. Moeller MP. Early intervention and language development in children who are deaf and hard of hearing. Pediatrics 2000;106(3):1-22. DOI: 10.1542/peds.106.3.e43.

23. Fryauf-Bertschy $\mathrm{H}$, Tyler RS, Kelsay DM, et al. Cochlear implant use by prelingually deafened children:the influences of age at implant and length of device use. J Speech Lang Hear Res 1997;40(1):183-199. DOI: 10.1044/jslhr.4001.183.

24. Connor CM, Hieber S, Arts HA, et al. Speech, vocabulary, and the education of children using cochlear implants: oral or total communication? J Speech Lang Hear Res 2000;43(5):1185-1204. DOI: 10.1044/jslhr.4305.1185.

25. Goycoolea M. Introduction and general perspective of sensorineural hearing loss. Rev Med Clin Condes 2016;27(6):721-730.

26. Lin FR, Yaffe $K, X i a ~ J$, et al. Hearing loss and cognitive decline in older adults. JAMA Intern Med 2013;173(4):293-299. DOI: 10.1001/ jamainternmed.2013.1868.

27. Hipoacusia DP. Un nuevo factor de riesgo para demencia. Rev Otorrinolaringol Cir Cabeza Cuello 2017;77(3):237-238. DOI: 10.4067/ s0718-48162017000300237.

28. Fromkin V, Krashen S, Curtiss S, et al. The development of language in genie: a case of language acquisition beyond the "critical period.". Brain Language 1974;1(1):81-107. DOI: 10.1016/0093-934X(74) 90027-3. 